\title{
Особенности строения липотейхоевых кислот бифидобактерий по данным ТСХ и ИК-ФТ
}

\author{
Сухих А.С., Захарова Ю.В. \\ ФГБОУ ВО «Кемеровский государственный медиџинский университет» Минздрава РФ, Кемерово \\ Поступила в редакцию 11.08.2017 г.
}

\begin{abstract}
Липотейхоевые кислоты (ЛТК) клеточной стенки представителей рода Bifidobacterium проанализированы методом ТСХ и ИК-ФТ. Экстракцию ЛТК из бактериальных клеток разных видов осуществляли смесью хлороформ : гексан. Установлены видовые отличия в хроматографических и спектральных характеристиках ЛТК бифидобактерий. Так, ЛТК B. bifidum характеризуются относительно высоким содержанием полиеновых фрагментов и остатков фосфорной кислоты. В свою очередь ЛТК B. breve отличаются низким содержанием непредельных фрагментов. Для B. longum характерно наличие в структуре ЛТК остатков фосфорной кислоты с тремя электроотрицательными заместителями. Установлены особенности разделения ЛТК разных видов бифидобактерий в условиях ТСХ. Показана возможность сравнительного анализа ЛТК грамположительных бактерий в режиме ТCX c последующим экстрагированием хроматографических зон и изучением в режиме ИК-ФТ.
\end{abstract}

Ключевые слова: липотейхоевые кислоты, ТСХ, ИК-ФТ, бифидобактерии.

\section{Features of structure lipoteichoic acids of Bifidobacteria according to TLC IR-FT}

\author{
Sukhikh A.S., Zakharova Yu.V. \\ Kemerovo State Medical University, Kemerovo
}

Bifidobacteria are representatives of human normoflora, they control the qualitative and quantitative composition of the community, prevent the excessive growth of opportunistic bacteria. A detailed study requires molecular mechanisms for the formation of biofilms on the mucosa, as well as, in fact, the initial stages of interaction of microflora with the intestinal wall. The features of the structure of LTA, which are a component of the cell wall of representatives of the genus Bifidobacterium, have not been studied in full. The aim of the study was the analysis of LTA of different types of bifidobacteria in the TLC regime.

The subject of the study were cultures of Bifidobacterium bifidum $379 \mathrm{M}$, and Bifidobacterium longum - isolated from probiotic preparations and a strain of Bifidobacterium breve obtained from a person with immunodeficiency. Isolation and accumulation of microbial mass of bifidobacteria was carried out by a routine bacteriological method. For this, bifidobacteria were grown 24 hours on liquid Bifidum-environment. Anaerobic conditions and gas-generating packets were used to create anaerobic conditions. Identification of bacteria was carried out on the basis of morphological, tinctorial, cultural and biochemical properties. The latter were studied using the commercial test systems ANAERO-TEST 23 (Lachema).

Extraction of LTK was carried out as follows. The bacterial mass was washed three times with an apyrogenic, sterile sodium chloride solution - resuspended for 2 minutes at Vortex and centrifugation at $5000 \mathrm{~g} 10 \mathrm{~min}$. Washed bacterial cells weighing $3.0 \mathrm{~g}$ (exact sample) were treated twice with $3 \mathrm{ml}$ of chloroform: $n$-hexane (1:1), followed by the combination of the organic phase. The solvents were distilled off in a stream of nitrogen.

Chromatography was performed on Sorbfil plates. The extract in a volume of $50 \mu 1$ was applied to the start line. Mobile phase: $\mathrm{CHCI}_{3}: \mathrm{MeOH}: \mathrm{H}_{2} \mathrm{O}(60: 30: 5)$ and using as a developer $5 \%$ phosphoricmolybdenum acid solution in EtOH. The chromatographic zones were extracted with $3 \mathrm{ml}$ of chloroform. The solvent was distilled off under a stream of nitrogen, in fractional application to a $\mathrm{KBr}$ disc. Fourier trans- 
form IR spectroscopy was performed on the FSM-1202 instrument. Chloroform extraction was fractionally applied to the $\mathrm{KBr}$ surface of the disk, (Fluka), the solvent was blown off with a nitrogen stream. The conditions for recording the spectra are as follows: the transmission mode, in the range $4000-400 \mathrm{~cm}-1$ with a resolution of $4 \mathrm{~cm}-1$ and the number of scans. 25. Air was used as a reference sample, a reference sample was recorded just before each sample was analyzed. Instrument control and processing of spectral data was carried out using the software Fspec (4.0.0.2) and Aspec (1.1).

For the samples studied, LTA is determined on the IR-spectra of all the chromatographic zones of the samples under investigation, in the interval $1755-1690 \mathrm{~cm}^{-1}$, the bands due to $v(\mathrm{C}=\mathrm{O})$ appear. Attention is drawn to the fact that LTA $B$. bifidum $379 \mathrm{M}$ in the chromatographic zones are most variable in this indicator. Thus, values from $1742 \mathrm{~cm}^{-1}\left(\mathrm{R}_{\mathrm{f}} 0.4\right)$ to $1712 \mathrm{~cm}^{-1}$ are traced. In turn, in all chromatographic zones of the $B$. breve sample, the absorption bands of 1744 and $1714 \mathrm{~cm}^{-1}$ are determined. The zone with $\mathrm{R}_{\mathrm{f}} 0.95$ is characterized by a band of $1744 \mathrm{~cm}^{-1}$. This variability of values is explained by the inductive effect of unsaturated fragments. The presence of a band of $1275 \mathrm{~cm}^{-1}$, which is present only in the sample of B. longum and corresponding phosphoric acid residues with three electronegative substituents, was observed. In the chromatographic zones corresponding to this sample, this band is traced at Rf values of 0.93 and 0.05 . It should be noted that the band $760 \mathrm{~cm}^{-1}$ corresponding to the valence vibrations of $\mathrm{C}-\mathrm{O}-\mathrm{P}$ is found only in $B$. breve samples, both in native LTA and after TLC. This band is detected at $\mathrm{R}_{\mathrm{f}}$ values of 0.25 ; 0.34; 0.97. Interestingly, for the LTA B. bifidum, three zones characteristic of phosphorus-bound bonds were found, with $\mathrm{R}_{\mathrm{f}}$ values of $0.41 ; 0.63 ; 0.92$. For these chromatographic zones, bands with a value of 800 and $772 \mathrm{~cm}^{-1}$ are characteristic. This bias in the B.bifidum sample is due to the presence of spatially close functional groups with which $\mathrm{P}=$ $\mathrm{O}$ can form a hydrogen bond. The resulted values of $\mathrm{R}_{\mathrm{f}}$ and the affiliation of these bands to phosphoruscontaining structures are consistent with the values of $\mathrm{R}_{\mathrm{f}}$ obtained after TLC treatment with phosphomolybdic acid. It should be noted that the spectral characteristics of chromatographic zones are variable. This property is apparently due to differences in structural fragments of LTA within one sample, which leads to a difference in the chromatographic mobility of varieties of LTA. In turn, it should be noted that the spectral parameters of LTA of the $B$. breve sample isolated from the chromatographic zones of TLC are relatively low. Thus, phosphorus-containing structures can be traced only in zones with $\mathrm{R}_{\mathrm{f}}$ values of 0.8-0.9. For this strain, For this strain, the lack of absorption bands in the range $1590-1530 \mathrm{~cm}^{-1}$ was rather specific. For a $B$. longum LTA sample in a range of $\mathrm{R}_{\mathrm{f}}$ values of $0.6-0.9$, a band of $1585 \mathrm{~cm}-1$ was detected. For LTA B. bifidum, similar structures are found in the range $\mathrm{R}_{\mathrm{f}}$ 0.3-0.95 with a maximum variation over the band $1587-1547 \mathrm{~cm}^{-1}$. It is known that strong absorption in the range 1650-1540 cm-1 can indicate an ionized carbonyl group, a planar deformation vibration of $\mathrm{NH}$ in amines, or stretching vibrations of $\mathrm{C}=\mathrm{O}$ in amines. In turn, LTA probiotic strains contain one broad band with a maximum of $1635 \mathrm{~cm}-1$, which is specific for polyene structures. Such strains of bifidobacteria can stimulate the immune system, which is the basis of the mechanisms of action of probiotic drugs.

Thus, a comparative analysis of LTA of representatives of the genus Bifidobacterium using the TLC method followed by analysis of IR-FT allowed to establish the distinctive chromatographic and spectral features of these structures. The distinctive features of the structure of LTA in a strain isolated from an individual with immunodeficiency were found. The application of the TLC version and the analysis of chromatographic zones in the IR spectroscopy mode can be used to study the component composition of samples obtained from plant objects and microorganisms, as well as to standardize probiotic preparations.

Keywords: Lipoteichoic acid, TLC, IR-FT, Bifidobacterium

\section{Введение}

Изучение факторов адгезии у представителей нормальной микрофлоры носит приоритетный характер. Это связано как с фундаментальным, так и с прикладным значением данных исследований, так как спектр бактериальных адгезинов довольно обширен. У грамположительных микроорганизмов - это белки клеточной стенки, полисахариды, тейхоевые и липотейхоевые кислоты (ЛТК). При этом ЛТК являются доминирующими анионными полимерами клеточной стенки с адгезивной функцией [1]. Это позволяет рассматривать ЛТК как компоненты для создания терапевтических средств, в том числе для коррекции микробиоценозов. В связи с этим требуются адекватные подходы для разделения очистки и стандартизации данной группы веществ микробного происхождения.

В настоящее время известно более 40 видов представителей рода Bifidobacterium [2]. При этом уместно предположить, что ЛТК бифидобактерий обладают отли- 
чительными видовыми структурными характеристиками. В этом контексте представляет интерес сопоставление строения ЛТК у бифидобактерий, имеющим разную видовую принадлежность и происхождение. Изучение структурно-функциональных свойств ЛТК тесно связано с применением методов хроматографии. За последние десятилетия были разработаны аналитические методы, которые позволяют непосредственно анализировать липидные компоненты клеточной мембраны, включая ЛТК, с использованием ВЭЖХ-МС. Как правило, липидоподобные структуры разделяются в соответствии с полярностью и идентифицируются многоступенчатой массспектрометрией [3]. Известен вариант анализа ЛТК с использованием ГХ-МС, где молекулу ЛТК подвергают кислотному гидролизу, а свободные жирные кислоты метилированию $[4,5]$. Данные варианты анализа характеризуются отсутствием возможности детальной идентификации структурных особенностей ЛТК, так как анализируется только липофильная часть ЛТК, представленная жирными кислотами.

В настоящее время ТСX все шире находит применение при разделении и анализе полифункциональных биомолекул [6] Детекция ЛТК осуществляется с использованием реагентов (проявителей). Данные подходы нарушают нативность молекулы ЛТК, не позволяя в полной мере оценить структурные видовые и штаммовые особенности. В данном варианте практически отсутствует возможность последующего анализа и сопоставления особенностей строения молекул ЛТК после хроматографического разделения и очистки. При этом аналитические возможности применения ТСХ в комбинации с ИК-ФТ при исследовании ЛТК не изучены. Поэтому, целью данной работы является анализ ЛТК разных видов бифидобактерий в режиме TCX.

\section{Теоретическая часть}

На сегодняшний день изучение ЛТК с использованием вариантов спектроскопии не позволяет в полной мере определить молекулярные особенности данных веществ. Так, с помощью спектральных методов исследования сложно оценить структурные различия заместителей в нативной молекуле ЛТК, таких как жирные кислоты, углеводороды в полиглицеролфосфатном фрагменте [7]. Поэтому, актуально исследование строения ЛТК с использованием методов хроматографии. При аналитическом режиме хроматографирования приобретает популярность ТСХ, совмещенная со спектральными методами детекции. Так, гликолипидная структура ЛТК Enterococcus faecalis изучена с использованием ТСХ/МАЛДИ-МС [8].

Особенности строения ЛТК обусловливают их биологические свойства, такие как адгезия, антигенность, иммуногенность [2, 5]. Иммуномодулирующее действие ЛТК из пробиотических бактерий значительно отличается от иммунологических эффектов ЛТК патогенных бактерий. Установлено, что основные различия между структурой ЛТК Staphylococcus aureus и пробиотического Lactobacillus plantarum определяются количеством и степенью насыщения ацильной цепи в гликолипидной части, типом модифицированных сахарных единиц в полиглицериновых фосфатных цепях, сопоставимостью уровней аланиновых заместителей [1]. Поэтому актуальным является вопрос исследования молекул в нативном состоянии без дериватизации и гидролиза.

\section{Эксперимент}

Объектом исследования были культуры Bifidobacterium bifidum 379 M, и Bifidobacterium longum - выделенные из пробиотических препаратов и штамм 
Bifidobacterium breve полученный от лица с иммунодефицитом. Выделение и накопление микробной массы бифидобактерий проводили рутинным бактериологическим методом. Для этого бифидобатерии выращивали 24 часа на жидкой Бифидум-среде (г. Оболенск), Для создания анаэробных условий применяли анаэростаты (BBL, США) и газогенерирующие пакеты (НПО «Новое дело», Санкт-Петербург). Идентификацию бактерий осуществляли на основании морфологических, тинкториальных, культуральных и биохимических свойств. Последние изучали с использованием коммерческих тест систем ANAERO-TEST 23 (Lachema, Чехия).

Экстракцию ЛТК осуществляли следующим образом. Бактериальную массу трижды отмывали апирогенным, стерильным раствором натрия хлорида - ресуспендировали на Vortex 2 мин и центрифугировании при 5000g 10 мин. Отмытые бактериальные клетки массой 3.0 г (точная навеска) двукратно обрабатывали смесью хлороформ : $н$-гексан (1:1) по $3 \mathrm{~cm}^{3}$, с последующим объединением органической фазы [5]. Растворители отгоняли в токе азота.

Хроматографию осуществляли на пластинах Sorbfil ПТСХ-АФ-А. Экстракт в объеме 50 мкл наносили на линию старта. Подвижная фаза: $\mathrm{CHCI}_{3}: \mathrm{MeOH}: \mathrm{H}_{2} \mathrm{O}$ (60:30:5) и использованием в качестве проявителя 5\% раствора кислоты фосфорномолибденовой в EtOH [8] .

Экстракцию хроматографических зон осуществляли $3 \mathrm{~cm}^{3}$ хлороформа. Растворитель отгоняли в токе азота, при дробном нанесении на $\mathrm{KBr}$ диск.

ИК-спектроскопия с Фурье преобразованием выполнена на приборе ФСМ1202 (Инфраспек, Россия). Хлороформное извлечение дробно наносили на поверхность $\mathrm{KBr}$ диска, (Fluka, Германия), растворитель отдувался током азота. Условия записи спектров следующие: режим пропускания, в диапазоне $4000-400 \mathrm{~cm}^{-1}$ с разрешением $4 \mathrm{~cm}^{-1}$ и числом сканов 25 . В качестве образца сравнения использовали воздух, запись образца сравнения проводили непосредственно перед анализом каждого образца. Управление прибором и обработка спектральных данных осуществляли с использованием программного обеспечения Fspec (4.0.0.2) и Aspec (1.1). При обработке спектральных данных использовали подход, изложенный в работе [9].

\section{Обсуждение результатов}

Структурно ЛТК являются амфифильными соединениями, состоящими из повторяющихся единиц альдитол-фосфата, углеговодного фрагмента и остатков жирных кислот рис. 1.

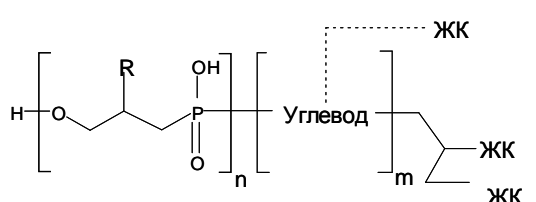

Рис. 1. Схема строения липотейхоевой кислоты, где ЖК-остатки жирных кислот

Синтез ЛТК является важным для жизнедеятельности микроорганизмов, так как они выполняют множество функций. Так, ЛТК способны обеспечивать связывание с двухвалентными катионами, участвуя в сорбции веществ из окружающей среды. С другой стороны, ЛТК способны образовывать ковалентные связи, в результате чего формируется электролитный гель и общий заряд клеточной поверхности, обеспечивающий взаимодействие с иммунокомпетентными клетками, с энтероцитами, с питательным субстратом. Специфическая лиганд-рецепторная адгезия бактерий 
происходит только после молекулярных взаимодействий между ЛТК микроорганизмов и клетками хозяина.

Состояние макроорганизма обусловливает особенности взаимодействия с бактериями, что способствует изменчивости структурных компонентов клеточной мембраны прокариот, в том числе и ЛТК. Поэтому уместно предположить, что ЛТК пробиотических штаммов и штамма, изолированного от человека с иммунодефицитом отличаются друг от друга.

Для изученных образцов ЛТК определяется наличие полос обусловленных ассиметричным валентным колебанием $2924 \mathrm{~cm}^{-1}$ и симметричным валентным колебанием $2854 \mathrm{~cm}^{-1}$ метиленовой групп. Характерно наличие полосы обусловленной сложноэфирным фрагментом (1750-1735 $\left.\mathrm{cm}^{-1}\right)$. Для штамма B.bifidum 379 М обнаружена полоса слабой интенсивности $1710 \mathrm{~cm}^{-1}$. Данные особенности соответствуют и компонентам экстрагированным с хроматографической пластины. Следует отметить, что на положение полосы оказывают влияние следующие факторы: электронные эффекты ближайших заместителей, соединения с кратными связями, а так же наличие меж- и внутримолекулярных водородных связей [10]. Рассматривая с этих позиций смещение полосы поглощения карбонильной группы, необходимо отметить следующее: наличие непредельных фрагментов в структуре ЛТК приводит к смещению полос поглощения в область низших частот. Подобной особенностью обладают ИКспектры ЛТК образца $B$. bifidum. На ИК-спектрах всех хроматографических зон исследуемых образцов, в интервале 1755-1690 см${ }^{-1}$ проявляются полосы обусловленные $v(\mathrm{C}=\mathrm{O})$. Обращает внимание тот факт, что ЛТК B. bifidum 379 М в хроматографических зонах наиболее вариативны по данному показателю. Так, прослеживаются значения от $1742 \mathrm{~cm}^{-1}\left(\mathrm{R}_{f} 0.4\right)$ до $1712 \mathrm{~cm}^{-1}$. В свою очередь, во всех хроматографических зонах образца B.breve определены полосы поглощения 1744 и $1714 \mathrm{~cm}^{-1}$. Зона с $\mathrm{R}_{f} 0,95$ характеризуется полосой $1744 \mathrm{~cm}^{-1}$. Данная вариативность значений, видимо объясняется индуктивным эффектом ненасыщенных фрагментов (остатков жирных кислот) которые изменяют силовую постоянную и частоту поглощения карбонильной группы. Следует отметить, что ЛТК от образца B. bifidum 379 М при всех значениях $\mathrm{R}_{f}$ обладают сопоставимой спектральной характеристикой карбонильного фрагмента.

Примечательно наличие полосы $1275 \mathrm{~cm}^{-1}$, присутствующей только у образца B. longum и соответствующей остаткам фосфорной кислоты с тремя электроотрицательными заместителями [11]. В хроматографических зонах, соответствующих данному образцу, данная полоса прослеживается при значениях $\mathrm{R}_{f} 0.93$ и 0.05 . Следует отметить, что полоса $760 \mathrm{~cm}^{-1}$ соответствующая валентным колебаниям C-О-Р обнаруживается только у образцов $B$. breve, как у нативной ЛТК, так и после ТСХ. Данная полоса обнаруживается при значениях $\mathrm{R} f 0.25 ; 0.34 ; 0.97$. Интересно, что для ЛТК B. bifidum обнаружено три зоны характерные для связей, обусловленных фосфором, со значениями $R_{f} 0.41 ; 0.63 ; 0.92$. Для этих хроматографических зон характерны полосы со значением 800 и $772 \mathrm{~cm}^{-1}$. Данное смещение у образца B. bifidum обусловлено наличием пространственно близких функциональных групп, с которыми $\mathrm{P}=\mathrm{O}$ может образовывать водородную связь [12]. Приведенные значения $\mathrm{R}_{f}$ и принадлежность данных полос к фосфорсодержащим структурам согласуются со значениями $\mathrm{R}_{f}$ полученными после обработки ТCX фосфорномолибденовой кислотой. Следует отметить, что спектральные характеристики хроматографических зон вариабельны. Данное свойство, видимо, обусловлено различиями в структурных фрагментах ЛТК в рамках одного образца, что приводит к различию в хроматографической подвижности разновидностей ЛТК рис. 2. В свою очередь, следует отметить относительно низкую вариативность спектральных показателей ЛТК выделен- 
ных из хроматогафических зон ТСX образца $B$. breve. Так, фосфорсодержащие структуры прослеживаются лишь в зонах со значениями $\mathrm{R} f$ 0.8-0.9. Для данного штамма достаточно специфичным оказалось отсутствие полос поглощения в интервале 1590-1530 см ${ }^{-1}$. Тогда как у образца ЛТК B. longum подвергнутого ТСХ в интервале значений $\mathrm{R}_{f}$ 0.6-0.9 обнаруживается полоса $1585 \mathrm{~cm}^{-1}$. Для ЛТК B. bifidum подобные структуры обнаруживаются в интервале $\mathrm{R}_{f} 0.3-0.95$ с вариацией максимума по полосе 1587-1547 $\mathrm{cm}^{-1}$. Известно, что сильное поглощение в интервале 1650$1540 \mathrm{~cm}^{-1}$ может указывать на ионизированную карбонильную группу, на плоскостные деформационные колебания $\mathrm{NH}$ в аминах, или валентные колебания $\mathrm{C}=\mathrm{O}$ в аминах [12].
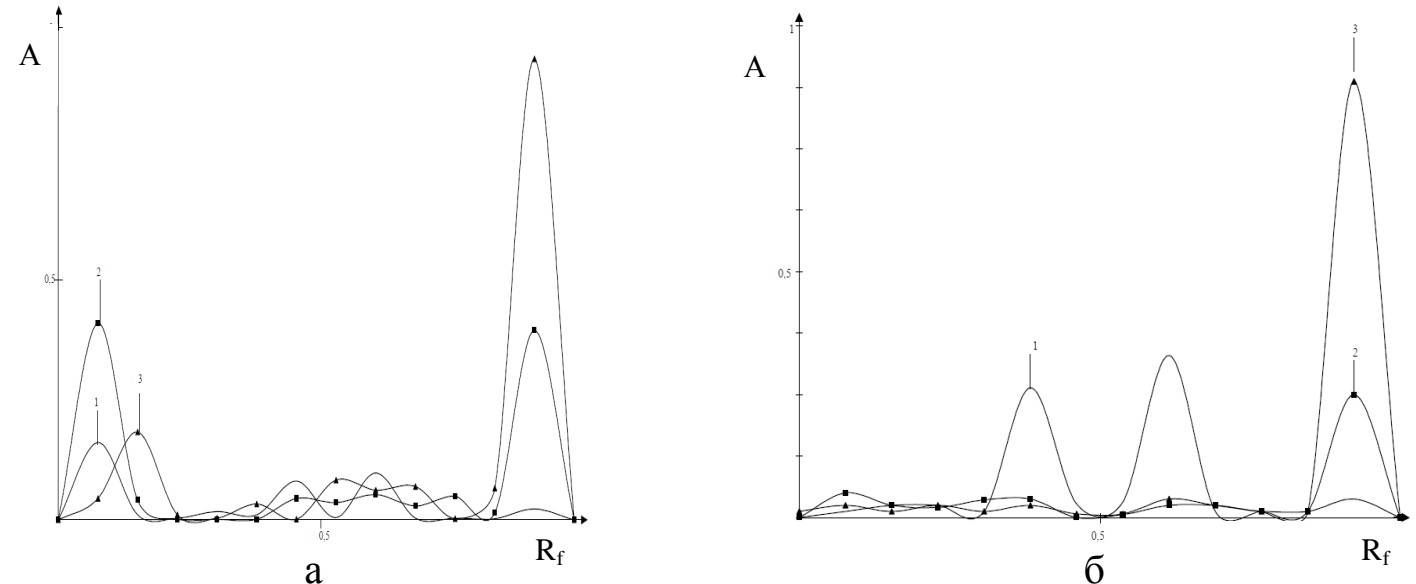

Рис. 2. Изменение интенсивности (v, $\left.\mathrm{cm}^{-1}\right)$ хроматографических зон образцов ЛТК по полосе: а) $1460 \mathrm{~cm}^{-1}$, б) $1022 \mathrm{~cm}^{-1}$; где 1 - B. bifidum 379 M; 2 - B. longum; 3 - B. breve.

Очевидно, что на данный показатель влияет гидрофильность остатков жирных кислот и электроотрицательность, обусловленная фрагментами фосфорной кислоты. Вместе с тем, данные особенности индивидуальны для каждого образца ЛТК и носят характерную видовую и штаммовую специфичность, что подтверждается данными ИК-спектроскопии экстрагированных участков ТСХ пластины рис. 3. Это позволяет использовать вариант ТСХ для стандартизации образцов ЛТК.

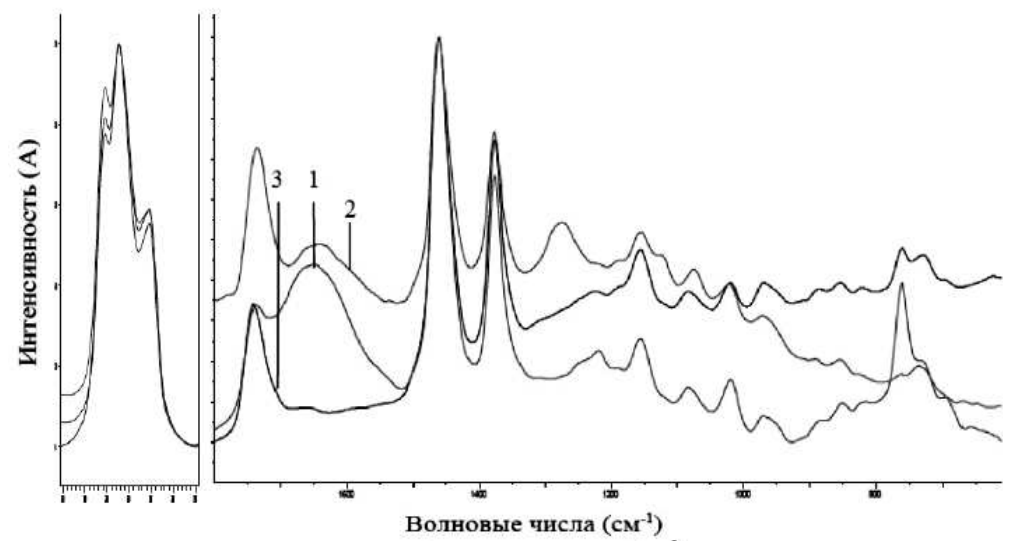

Рис. 3. Спектры ИК-ФТ образцов ЛТК экстрагированных из хроматографической зоны с Rf 0,95 ; где 1- B. bifidum 379 M; 2- B. longum; 3- B. breve

Известно, что биологическая активность ЛТК связана с наличием аланинового фрагмента и степенью насыщенности жирнокислотных цепей молекулы. Именно остатки ЖК непосредственно влияют на интенсивность воспалительных реакций, 
так как длина цепи жирных кислот с высокой степенью насыщения коррелирует с более сильной воспалительной реакцией [13]. У образца ЛТК B. breve, который получен от лица с иммунодефицитом, по данным ИК-ФТ практически отсутствует область характерная для диеновых фрагментов, что предопределяет низкую иммуностимулирующую активность данного штамма. В свою очередь ЛТК пробиотических штаммов, содержат одну широкую полосу с максимумом $1635 \mathrm{~cm}^{-1}$, что специфично для полиеновых структур. Такие штаммы бифидобактерий позволяют стимулировать иммунную систему, что и лежит в основе механизмов действия пробиотических препаратов.

\section{Заключение}

Таким образом, сравнительный анализ ЛТК представителей рода Bifidobacterium с использованием метода ТСХ с последующим анализом ИК-ФТ позволил установить отличительные хроматографические и спектральные особенности данных структур. Так, ЛТК пробиотического штамма B. bifidum 379 M характеризуются относительно высоким содержанием полиеновых фрагментов и остатков фосфорной кислоты. В свою очередь ЛТК $B$. breve отличаются низким содержанием непредельных фрагментов. Для образца $B$. longum характерно наличие в структуре ЛТК остатков фосфорной кислоты с тремя электроотрицательными заместителями. Применение варианта ТСХ с последующим анализом хроматографических зон в режиме ИКспектроскопии, может использоваться при изучении компонентного состава образцов полученных из растительных объектов и микроорганизмов, а также для стандартизации пробиотических препаратов.

\section{Список литературы}

1. Wanga J., Qia L., Wua Z., Meia L., Wangba H. // International Journal of Biological Macromolecules. 2016. Vol. 87. pp. 481-487.

2. Захарова Ю.В. // Журнал микробиологии, эпидемиологии и иммунобиологии. 2016. № 5. C. 80-87.

3. Chena G., Songa C., Jinb S., Lia S. et al. // Talanta. 2017. Vol. 162. pp. 530-539.

4. Masood M.A., Blonder J., Veenstra T.D. // Journal of Pharmaceutical Sciences. 2017. Vol.106. No.7. pp. 1760-1763.

5. Захарова Ю.В., Сухих А.С. // Сорбционные и хроматографические прочессы. 2015. T. 15. № 6. C. 776-783.

6. Xu L., Wang Z., Mao P., Liu J. et al. // Bioresource Technology. 2013. Vol. 133. pp. 635-637.

7. Jang K.-S., Baik J.E., Han S.H. // Biochemical and Biophysical Research Communications. 2011. Vol. 407. pp. 823-830.

\section{References}

1. Wanga J., Qia L., Wua Z., Meia L., Wangba H., International Journal of Biological Macromolecules.,2016, Vol. 87, pp. 481-487.
8. Baik J.E., Jang K.-S, Kang S.-S. et al. // Journal of Endodontics. 2011. Vol. 37. No 2. pp.191-196.

9. Федорова Н.И., Заостровский А.Н., Исмагилов 3.Р. // Вестник КузГТУ. 2015. №.5. C. $126-129$.

10.Сильверстейн Р., Вебстер Ф., Кимл Д.М. Спектрометрическая идентификация органических соединений. М. БИНОМ. 2011. 557 c.

11.Беллами Л. Инфракрасные спектры сложных молекул. М. 1963. 590 с.

12.Смит А. Прикладная ИК-спектроскопия М. Мир. 1982. 328 c.

13.Han S.H., Kim J.H., Martin M., Michalek S.M. et al. // Infection and immunity. 2003. Vol. 71. No. 10. pp. 5541-5548.

2. Zaharova Yu.V., Zhurnal mikrobiologii, jepidemiologii i immunobiologii, 2016, No 5, pp. 80-87. 
3. Chena G., Songa C., Jinb S., Lia S. et al., Talanta, 2017, Vol. 162, pp. 530-539. doi: 10.1016/j.talanta.2016.10.045

4. Masood M.A., Blonder J., Veenstra T.D., Journal of Pharmaceutical Sciences. 2017, Vol. 106, No 7, pp. 1760-1763. doi: 10.1016/j.xphs.2017.02.034

5. Zaharova Yu.V., Suhih A.S., Sorbtsionnye $i$ khromatograficheskie protsessy, 2015, Vol. 15, No 6, pp. 776-783.

6. Xu L., Wang Z., Mao P., Liu J. et al., Bioresource Technology, 2013, Vol. 133, pp. 635637.

7. Jang K.-S., Baik J.E., Han S.H. Biochemical and Biophysical Research Communications, 2011, Vol. 407, pp. 823-830.

Сухих Андрей Сергеевич - ст. науч. сотр. ЦНИЛ к.фарм.н., доцент, «Кемеровский государственный медицинский университет» Минздрава РФ, Кемерово. 8(3842) 52-10-18

Захарова Юлия Викторовна - доцент кафедры микробиологии иммунологии и вирусологии, к.м.н., ФГБОУ ВО «Кемеровский государственный медицинский университет» Минздрава РФ, Кемерово
8. Baik J.E., Jang K.-S, Kang S.-S., et al., Journal of Endodontics, 2011, Vol. 37, No 2, pp.191-196. doi: 10.1016/j.joen.2010.11.007

9. Fedorova N.I., Zaostrovskij A.N., Ismagilov Z.R., Vestnik KuzGTU, 2015, No 5, pp. 126129.

10. Sil'verstejn R., Vebster F., Kiml D.M., Spektrometricheskaja identifikacija organicheskih soedinenij, M., BINOM, 2011, 557 p.

11. Bellami L., Infrakrasnye spektry slozhnyh molekul, M., 1963, 590 p.

12. Smit A., Prikladnaja IK-spektroskopija, M., Mir, 1982, 328 p.

13. Han S.H., Kim J.H., Martin M., Michalek S.M. et al., Infection and immunity, 2003, Vol. 71, No. 10 .pp. 5541-5548. doi: 10.1128/IAI.71.10.5541-5548.2003.

Sukhikh Andrey S. - Ph.D. (pharm.), senior scientific worker of CSRL Kemerovo State Medical University, Kemerovo, Kemerovo. e-mail: $\underline{\mathrm{Su}}-$ hih_as@list.ru

Zakharova Yulia V. - Ph.D. (medical) associate senior lecturer chair of microbiology immunology and virology Kemerovo State Medical University, Kemerovo 